\title{
Morphology of immune organs after very virulent plus strain of Marek's disease virus infection in vaccinated hens
}

\author{
J.P. Madej', G. Woźniakowski², A. Gaweł ${ }^{3}$ \\ ${ }^{1}$ Department of Histology and Embryology, Faculty of Veterinary Medicine, \\ Wrocław University of Environmental and Life Sciences, Norwida 25, 50-375, Wrocław, Poland \\ ${ }^{2}$ Department of Swine Diseases, National Veterinary Research Institute Pulawy (NVRI), \\ al. Partyzantów 57, 24-100 Puławy, Poland \\ ${ }^{3}$ Department of Epizootiology and Clinic of Bird and Exotic Animals, Faculty of Veterinary Medicine, \\ Wrocław University of Environmental and Life Sciences, pl. Grunwaldzki 45, 50-355 Wrocław, Poland
}

\begin{abstract}
Marek's disease (MD) outbreaks in poultry flocks may be associated with overriding of vaccine immune protection by very virulent (vvMDV) or very virulent plus (vv+MDV) strains. This paper presents the study on lymphoid organ morphology in the latent phase of MD caused by vv+MDV which break post-vaccinal protection in hens. We also immunohistochemically examined $\mathrm{B}$ and $\mathrm{T}$ populations as well as $\mathrm{B} / \mathrm{T}$ and $\mathrm{CD} 4^{+} / \mathrm{CD}^{+}$ratio of lymphocytes in lymphatic organs and, as a background, in MD lymphomas from non-lymphatic organs. The number of antigen expressed cells was evaluated as a percentage of positive cells in the one power field. Organ samples were collected from 24 dead reproductive hens (Ross 308 line) in age between 35-56 weeks, infected with vv+MDV. The hens originated from farms with MD outbreaks, despite earlier routine vaccination with CVI988/Rispens + HVT. The control organ samples originated from 15 clinically healthy hens at the same age and line, subjected to the same vaccination schedule. The number of $\mathrm{CD}^{+}, \mathrm{CD}^{+}$and $\mathrm{TCR} \gamma \delta^{+}$cells was significantly lower in MDV infected thymus, spleen and cecal tonsils in comparison to that found in the control organs. The proportion of $\mathrm{CD}^{+}{ }^{+}$was also distinctly reduced in the thymus and limited in the spleen of MDV infected hens. This study revealed that infection with field vv+MDV isolates might break post-vaccinal protection and influence the central and peripheral immune system. The decrease in $\mathrm{CD}^{+}$and $\mathrm{TCR} \gamma \delta^{+}$cell number in the thymus, spleen and cecal tonsils suggests that primarily these cells are involved in cell-mediated cytotoxicity against MDV transformed cells during latency.
\end{abstract}

Key words: Marek's disease, MDV, immune system, chicken, morphology, latent phase 


\section{Introduction}

Marek's disease virus (MDV) is an oncogenic alpha-herpesvirus that belongs to the Mardivirus genus. Three serologically distinct serotypes of MDV comprising of Gallid herpesvirus 2 (GaHV-2, MDV-1), which causes tumors in susceptible chickens, and two non-oncogenic species, Gallid herpesvirus 3 (GaHV-3, MDV-2) and Meleagrid herpesvirus 1 (MeHV-1, HVT) (Osterrieder et al. 2006, Schat and Venugopal 2008) have been described. MDV-1 strains are further classified into four pathotypes: mild (m), virulent $(\mathrm{v})$, very virulent $(\mathrm{vv})$, and very virulent plus $(\mathrm{vv}+)$ (Witter 1983, 1997, Witter et al. 2005).

Infection in chickens starts with a cytolytic infection in B cells involving the lymphoid organs followed by a latent infection in T cells (Schat and Xing 2000). MDV latency is mostly associated with activation of $\mathrm{CD}^{+} \mathrm{T}$ cells. Some of them are transformed by the virus, although $\mathrm{CD}^{+} \mathrm{T}$ cells and $\mathrm{B}$ cells can also be latently infected (Venugopal 2000, Schat and Venugopal 2008). Transformed T lymphocytes subsequently lead to the development of gross lymphomatous (proliferative or less often inflammatory) lesions in visceral organs with accompanying immunosuppression (Burgess and Davison 1999). Recent studies presented by Mwangi et al. (2011) indicated that MDV driven lymphomas are dominated by highly restricted number of $\mathrm{CD}^{+}{ }^{+}$clones indicating monoclonal or oligoclonal origin of these tumors. The switch from cytolytic to latent phase occurs about one week post infection (Schat and Xing 2000).

The immune reaction against MDV involves innate and adaptive immune responses (Haq et al. 2013). Since MDV is a highly cell-associated herpesvirus, it has been demonstrated that cytotoxic $\mathrm{T}$ lymphocytes (CTLs) are involved in specific responses and are directed towards cells expressing immediate-early, early and late MDV antigens (Omar and Schat 1996). The CTL were characterized as $\mathrm{CD}^{+}{ }^{+} \mathrm{TCR}_{2}{ }^{+}$cells, while the $\mathrm{CD} 4^{+}$and $\mathrm{TCR} 1^{+}$cells are not important for the elimination of MDV antigen-expressing cells (Omar and Schat 1997). The responding $\mathrm{CD}^{+} \mathrm{T}$ cell infiltrates are oligoclonal indicating recognition of a limited number of $\mathrm{MDV}$ antigens (Mwangi et al. 2011). The specific humoral immune response includes production of antibodies against MDV glycoproteins such as $\mathrm{gB}, \mathrm{gE}$, and $\mathrm{gI}$. These antibodies may contribute to the immunity against MDV by neutralizing cell-free viruses, blocking entry of the virus into cells, and antibody-dependent cell-mediated cytotoxicity (ADCC) (Kodama et al. 1979, Ross 1980). However, the exact role of the antibody-mediated immune response has been not clearly established (Haq et al. 2013).
The worldwide method of protection against MDV is common vaccination of poultry flocks. There are two mechanisms responsible for the protection. Firstly, the similarity of antigens between vaccine and virulent strains stimulates an immune response, resulting in inhibition of viral replication and spread, leading to decreased malignant transformation and reduction of immunosuppression. Secondly, MDV tumor antigens stimulate the immunological destruction of tumor cells by CTLs (Powell and Rennie 1978; Baigent et al. 2006). Unfortunately, MD vaccines are incapable of inducing a sterile immunity and allow the virulent virus strains to replicate and be transmitted into the environment through the vaccinated host (Zhang et al. 2015). It is believed, that keeping host alive, vaccination prolongs the infection time of virulent strains and may cause evolution of MDV with increased virulence (Witter 1997, Atkins et al. 2013, Hunt and Dunn 2013, 2015). This is why more virulent MDV pathotypes emerge, reducing the effectiveness of existing vaccines (Davison and Nair 2005, Hunt and Dunn 2015, Zhang et al. 2015). Witter (1997) proposed a classification system where virulent MDV (vMDV) induced lesions in turkey herpesvirus (HVT) vaccinated chickens at a rate comparable to the $\mathrm{JM} / 102 \mathrm{~W}$ virus strain infected. Very virulent MDV (vvMDV) was assigned to those strains inducing lesions in HVT vaccinated chickens at a rate greater than those found in $\mathrm{JM} / 102 \mathrm{~W}$ strain infected and in bivalent-vaccinated chickens at a rate comparable to those observed in the Md5 strain infected animals. The very virulent plus MDV (vv+MDV) was assigned to isolates causing lesions in bivalent-vaccinated chickens at a rate greater than those found in the Md5 strain infected animals. The indirect effect of continuous MDV evolution is the concurrent infection of chickens with vaccine and pathogenic MDV strains. In the early 1990 s, major outbreaks of MD occurred. These were associated with the emergence of $\mathrm{vv}+\mathrm{MDV}$ and the failure of previously used, bivalent $(\mathrm{HVT}+\mathrm{MDV}-2)$ vaccine protection (Witter 1996, 1997). This is why Rispens (CVI988) vaccine, an attenuated mild MDV-1, which provided superior protection against $\mathrm{vv}+\mathrm{MDV}$, was introduced to mass vaccination (Witter et al. 1995). The MDV pathotype can be determined using standardized chicken trial (Dudnikova et al. 2007). However, the previous analysis of nucleotide and amino acid sequences of meq oncogene (LORF7), or LORF6 and $23 \mathrm{kDa}$-encoding protein regions derived from the reference $\mathrm{MDV}$ strains with in vivo determined pathotype revealed some similar sequence motifs that might be related to the true MDV pathotype (Woźniakowski et al. 2014).

This paper presents the morphology and immune cell composition in lymphoid organs in the latent 
phase of MD caused by vv+MDV infection which breaks post-vaccinal protection in hens. In addition, in this work we estimated the $\mathrm{B}, \mathrm{T}$ and $\mathrm{T} \gamma \delta$ (TCR1) populations as well as $\mathrm{B} / \mathrm{T}$ and $\mathrm{CD} 4^{+} / \mathrm{CD}^{+}$ratios of lymphocytes in lymphatic organs and, as a background, in MD lymphomas from non-lymphatic organs. We aimed to answer how the adaptive immune system of the host react to the presence of highly virulent MDV strain. Because MDV infection alters the microbial composition of the intestinal tract (Heidari et al. 2014, Perumbakkam et al. 2014), it was reasonable to investigate how the infection influenced the lymphocyte profile in gut-associated lymphoid tissue represented by cecal tonsils (CT).

\section{Materials and Methods}

\section{Materials}

The MD group consisted of 24 dead hens (Ross 308 line), 35-56 weeks of age, infected with vv+MDV. The hens came from commercial breeding farms with outbreaks of MD, despite earlier routine vaccination against MDV with CVI988/Rispens + HVT in the first day of life. The virus strain was identified in the reference MD laboratory at the National Veterinary Institute in Pulawy (NVRI) using the PCR method and subsequent direct DNA sequencing of LORF7 (meq) region, and then nucleotide and amino acid alignment using Genius R7 software (Biommaters, Auckland, New Zealand) with the reference strains accessible in the NCBI GenBank database, as previously described by Woźniakowski et al. (2014). Organ samples of the spleen, thymus, cecal tonsil, lung, liver, kidney, proventriculus, ileum, ovarium, sciatic nerve, skin and skeletal muscles were collected from dead hens, 3 to 12 weeks after MD outbreak in the flock.

The control set of organ samples came from 15 clinically healthy hens, of the same age and line as those in the MD group, maintained in the same region of country but in different flocks. The control hens were subjected to the same vaccination schedule. The experiments were conducted with the consent of the Local Ethics Committee for Animal Experiments (19/2012, Poland).

\section{Histopathological examination}

All collected organ samples were bisected into two sub-samples. The bursa of Fabricius was not analyzed due to a significant atrophy of this organ. The first sub-sample was fixed in $4 \%$ phosphate buffered paraformaldehyde ( $\mathrm{pH} 7.4$ ) for $1 \mathrm{~h}$, washed in $0.1 \mathrm{M}$ phos- phate buffer and infiltrated with buffered $30 \%$ sucrose. Then, it was cut into $10 \mu \mathrm{m}$ serial sections in a cryostat (Leica CM1850, Leica Microsystems GmbH, Wetzlar, Germany), aired-dried overnight and frozen. The second sub-sample was fixed in $4 \%$ buffered formaldehyde ( $\mathrm{pH}$ 7.4) and embedded in paraffin wax. Sections ( $3 \mu \mathrm{m}$ thick) of each sample were stained with Mayer's hematoxylin (Roth GmbH, Karlsruhe, Germany) and eosin (Poch S.A., Gliwice, Poland). The slices were examined and photographed under a light microscope (Nikon Eclipse 80i; Nikon, Melville, NY, USA) with a video camera. Only those individuals who had typical MD lymphomas in at least three non-lymphatic organs were subjected to immunohistochemical study.

\section{Immunohistochemistry}

After thawing, the sections were air-dried, and fixed in hydrogen peroxide solution to quench endogenous peroxidase, and incubate for 20 minutes with Antibody Diluent with a Background Reducing Component (Dako, Glostrup, Denmark) for blocking non-specific binding. The serial sections were incubated at room temperature for 1 hour with monoclonal mouse anti-chicken antibodies (Southern Biotech, Birmingham, AL, USA) directed against antigens: Bu-1 (clone AV20, 1:500), CD3 (clone CT-3, 1:200), CD4 (clone CT-4, 1:200), CD8 $\alpha$ (clone CT-8, 1:200) and TCR $\gamma \delta$ (clone TCR-1, 1:100). Anti Bu-1 antibody recognizes a monomorphic determinant on the Bu-1 B-cell associated alloantigens of both RPL6 (Bu-1a) and RPL7 (Bu-1b) lines of inbred chickens (Rothwell et al. 1996, Igyarto et al. 2008). The visualization of the antigens was performed using EnVision $^{\mathrm{TM}}$ Systems (Dako), according to the manufacturer's instructions. All sections were counterstained with Mayer's hematoxylin.

\section{Morphometry}

The area occupied by the antigen-positive cells was measured on an area of $290,000 \mu \mathrm{m}^{2}(200 \times$ magnification) using an NIS-Elements AR 2.30 (Nikon) program and expressed as a percentage of the field of view. Any false positive artifacts were in each case eliminated by a histologist. In the thymus, the fields of view were always selected starting from the capsule so that the whole cortex and outer part of the medulla were analyzed. In CT, the fields of view were always selected starting from the lamina propria mucosae in the direction of the lumen of the organ. In order to compare the number of cells in each staining $(\mathrm{Bu}-1$, 
CD3, CD4, CD8 $\alpha$ and TCR $\gamma \delta$ ), the analyzed fields of view were selected from the same place in adjacent serial sections of the organ. The $\mathrm{Bu}-1^{+} / \mathrm{CD}^{+}$and $\mathrm{CD}^{+} / \mathrm{CD}^{+}$cell ratios were calculated for each field of view. In non-lymphatic organs, only areas with massive lymphomas were selected (reading frame) and analyzed to determinate the $\mathrm{B} / \mathrm{T}\left(\mathrm{Bu}-1^{+} / \mathrm{CD}^{+}\right)$ and $\mathrm{Th} /$ cytotoxic cell $\left(\mathrm{CD}^{+} / \mathrm{CD}^{+}\right)$ratios. The way of analysis and calculation method were similar in both lymphatic and non-lymphatic organs.

\section{Statistical analysis}

The morphometric data were analyzed using Statistica 12.5 software (StatSoft Polska, Cracow, Poland). The significance of differences was assessed using either the Student's t-test or the Mann-Whitney $\mathrm{U}$ test, according to the normality of data distribution. A value of $p<0.05$ was considered significant.

\section{Results}

\section{Anatomopathological changes}

The pathological changes observed in MD group were marked atrophy of the ovary (92\%), marked atrophy of the spleen (42\%), mild splenomegaly (33\%), hepatomegaly (17\%), tumors in the liver $(36 \%)$, kidneys (20\%), small intestine (17\%), skeletal muscles (17\%) and skin (12\%), as well as thickening of the sciatic nerve $(17 \%)$.

\section{Histopathological examination}

In the spleen of MD group mild to moderate decrease in the number of lymphocytes in periarteriolar lymphoid sheath $(33 \%)$, mild decrease in the number of lymphocytes in follicles (29\%), congestion of the red pulp (13\%), and blurring of the boundary between the red and white pulp (17\%) were observed. In the thymus, the narrowing of the cortex $(83 \%)$, blurring of the cortico-medullary border $(67 \%)$, and congestion of the medulla (42\%) were noted.

In non-lymphatic organs, numerous, massive lymphomas occurred. These were particularly frequently observed in kidneys (62\% of birds with lesions), liver $(46 \%)$, skeletal muscles $(33 \%)$ and proventriculus $(29 \%)$, but were also present in the ovarium $(17 \%)$, skin $(17 \%)$ and ileum (13\%). In the sciatic nerve, mild to marked heterogeneous infiltration of lymphocytes and lymphoblasts were also frequently (33\%) observed.

\section{Immunohistochemistry}

\section{Topography of the immune cells}

In the thymus in both MD and control groups, $\mathrm{Bu}-1^{+}$cells were present in large numbers in the medulla, whereas in the cortex they were scattered and only occasionally encountered (Fig. 1). In the control group, the $\mathrm{CD}^{+}$lymphocytes were present both in the cortex and in the medulla, while in the MD group the cortex was markedly depopulated from these cells. The $\mathrm{CD}^{+}$cells in the control group were densely packed in the cortex, but in the medulla they appeared singly or in the form of small foci. In the MD group, the density of cortical $\mathrm{CD}^{+}$cells decreased from the level in the medulla. $\mathrm{CD}^{+}$cells were mainly observed in the cortex in both groups investigated, but in the MD group they occurred in lower numbers.

The topography of immune cells in the spleen from MD group was generally similar to that in the controls, but the numbers of specific population cells were markedly affected (Fig. 2). The B-dependent zone $\left(\mathrm{Bu}-1^{+}\right)$formed a peri-ellipsoidal white pulp (PWP) which surrounds the penicillary capillaries, but the germinal centers (GC) were rarely visible. Around the central arteries, typical T-dependent zones $\left(\mathrm{CD}^{+}\right)$called peri-arteriolar lymphatic sheath (PALS) were present which formed inner-mainly $\mathrm{CD} 4^{+}$layer and outer $\mathrm{CD} 8^{+}$and $\mathrm{TCR} \gamma \delta^{+}$sheets.

Distributions of examined immune cells within CT were similar in MD and control groups. Bu- $1^{+}$cells were observed in large numbers within mid-and deep portions of the mucosa, mainly forming GC but also as cells scattered in interfollicular zones (Fig. 3). The $\mathrm{CD}^{+}$cells were found mainly in interfollicular zones as $\mathrm{CD} 4^{+}$cells, subepithelially as $\mathrm{CD} 4^{+}$or $\mathrm{CD}^{+}$cells and intraepithelially as $\mathrm{CD} 8^{+}$cells. $\mathrm{TCR} \gamma \delta^{+}$cells were observed as single cells scattered within all the above-mentioned zones.

In the lungs of $\mathrm{vv}+\mathrm{MDV}$ infected hens, $\mathrm{CD}^{+}{ }^{+} \mathrm{CD} 4^{+}$cells massively occupied the connective tissue between respiratory units, between air capillaries and around inter-and intraparabronchial vessels, while in the control chickens they were sparsely distributed. In the wall of secondary bronchi, these cells were scattered and not so numerous. In the MD group, $\mathrm{CD}^{+}$cells had a similar location to that of $\mathrm{CD}^{+}$cells, but they were sparse while in the controls they were usually present in the lining of the atria. In both groups, B cells were arranged in typical GC in the walls of secondary bronchi and around interparabronchial vessels. In lungs with massive lymphomas, stimulation of normal lymphoid follicles within bronchus-associated lymphoid tissue (BALT) was frequently observed. 

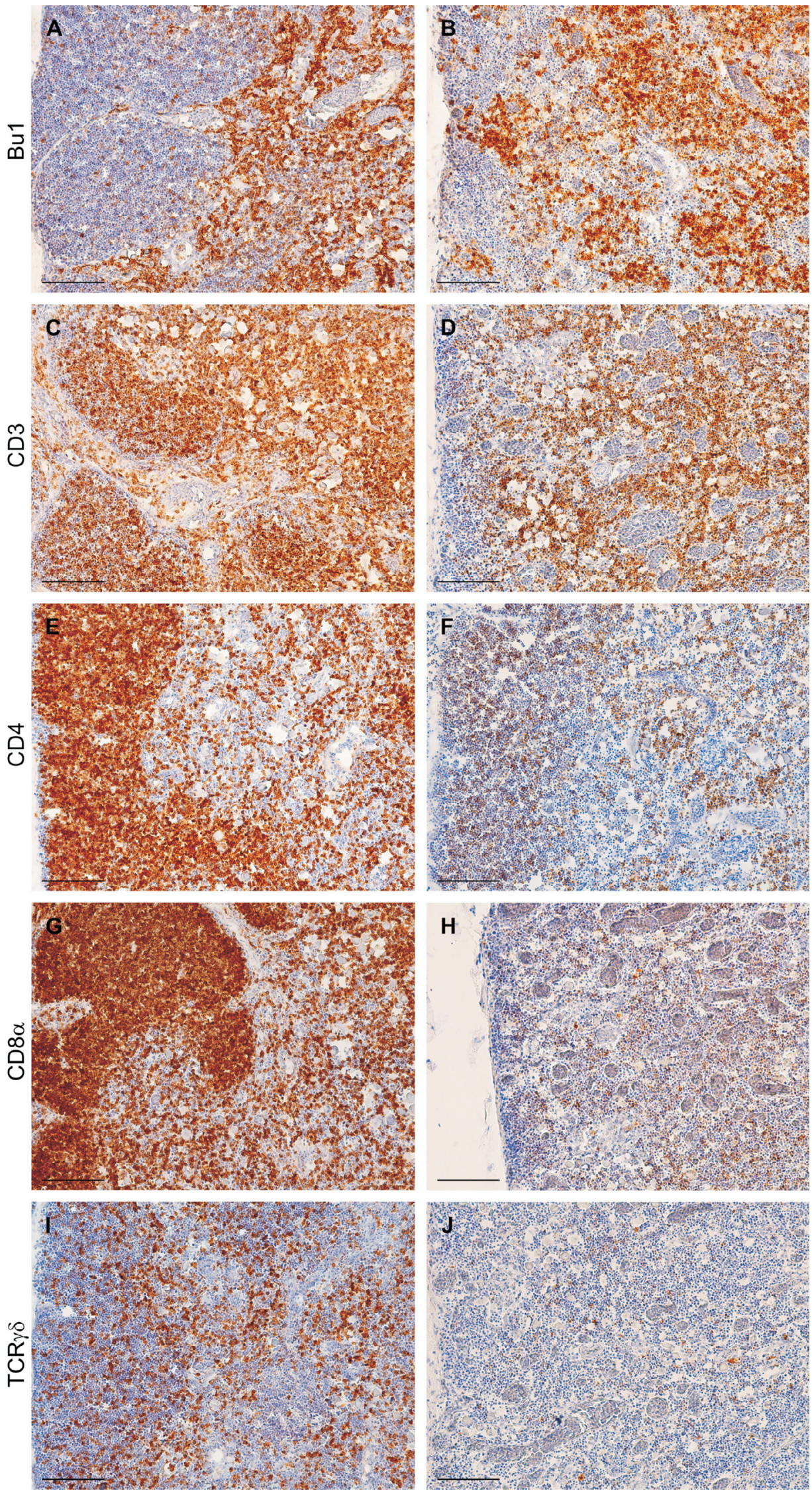

Fig. 1. Examples of immune cell antigen (Bu1, CD3, CD4, CD8 $\alpha$ and TCR $\gamma \delta$ ) expression and distribution in the thymus in the control (A, C, E, G, I) and vv+MDV infected (B, D, F, H, J) hens. In the MD group, the cortex was prominently narrowed, and the number of $\mathrm{CD}^{+}, \mathrm{CD}^{+}, \mathrm{CD} 8 \alpha^{+}$and $\mathrm{TCR} \gamma \delta^{+}$cells was significantly reduced. Original magnification $200 \times$, scale bar $=100 \mu \mathrm{m}$. 

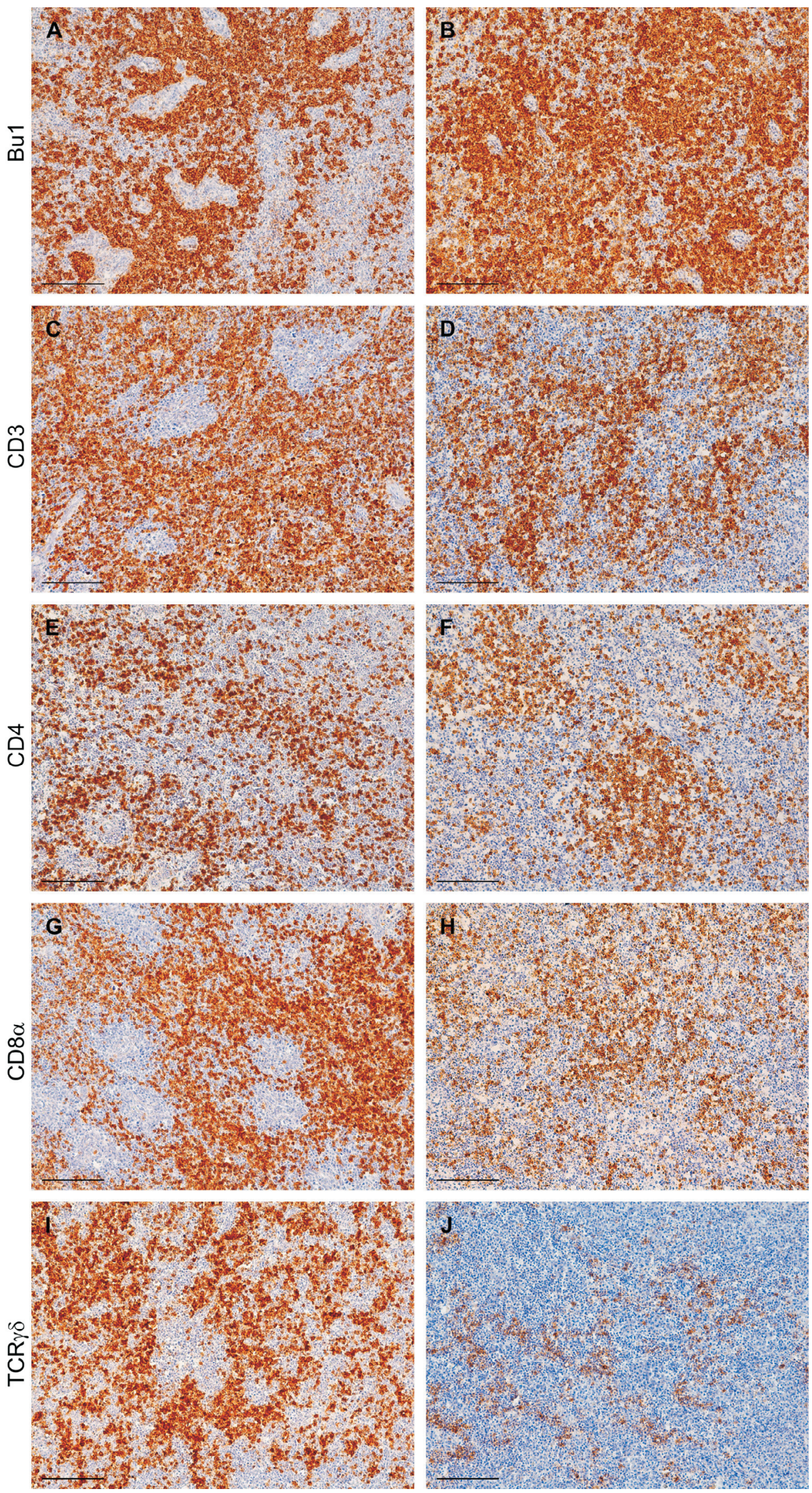

Fig. 2. Examples of immune cell antigen (Bu1, CD3, CD4, CD8 $\alpha$ and TCR $\gamma \delta$ ) expression and distribution in the spleen in the control $(\mathrm{A}, \mathrm{C}, \mathrm{E}, \mathrm{G}, \mathrm{I})$ and $\mathrm{vv}+\mathrm{MDV}$ infected $(\mathrm{B}, \mathrm{D}, \mathrm{F}, \mathrm{H}, \mathrm{J})$ hens. In the MD group, the number of $\mathrm{CD} 3^{+}, \mathrm{CD} 8 \alpha^{+}$and $\mathrm{TCR} \gamma \delta^{+}$cells was markedly reduced, whereas the number of $\mathrm{CD}^{+}$cells was moderately lower. Original magnification $200 \times$, scale bar $=100 \mu \mathrm{m}$. 

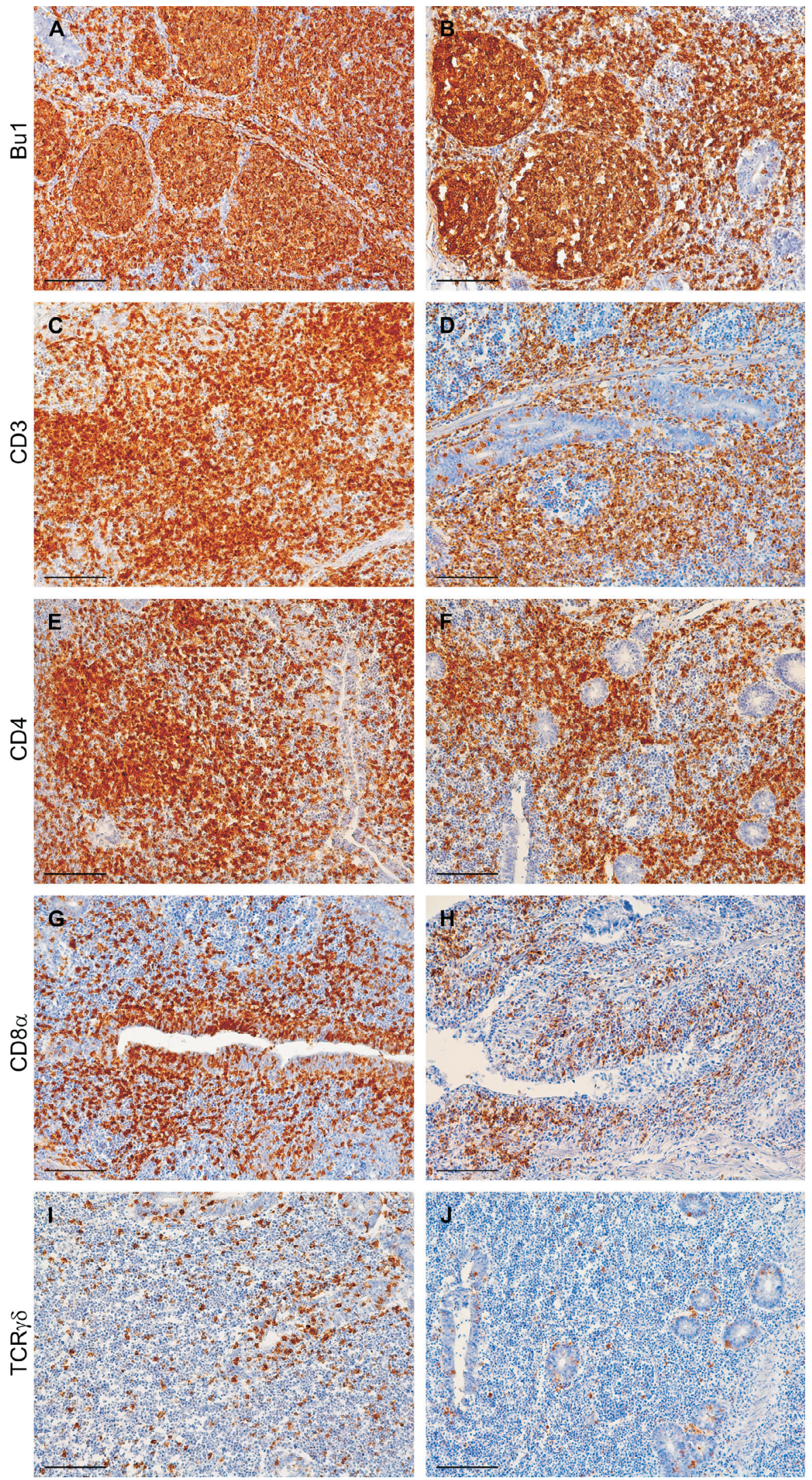

Fig. 3. Examples of immune cell antigen (Bu1, CD3, CD4, CD $8 \alpha$ and TCR $\gamma \delta)$ expression and distribution in cecal tonsils in the control (A, C, E, G, I) and vv+MDV infected (B, D, F, H, J) hens. Markedly reduced number of CD3 ${ }^{+}, \mathrm{CD} 8 \alpha^{+}$and $\mathrm{TCR} \gamma \delta^{+}$ cells in MD group. A, B-the Bu1 $1^{+}$cells forming typical GC; $\mathrm{C}, \mathrm{D}-\mathrm{CD} 3^{+}$cells located between $\mathrm{GC}$ as well as supra- and intraepithelially; E, F-CD4 ${ }^{+}$cells in interfollicular and subepithelial zones; G, H-sub- and intraepithelially located $\mathrm{CD}^{+}$cells, I, $\mathrm{J}-\mathrm{TCR} \gamma \delta^{+}$cells scattered within all above mentioned zones. Original magnification $200 \times$, scale bar $=100 \mu \mathrm{m}$. 


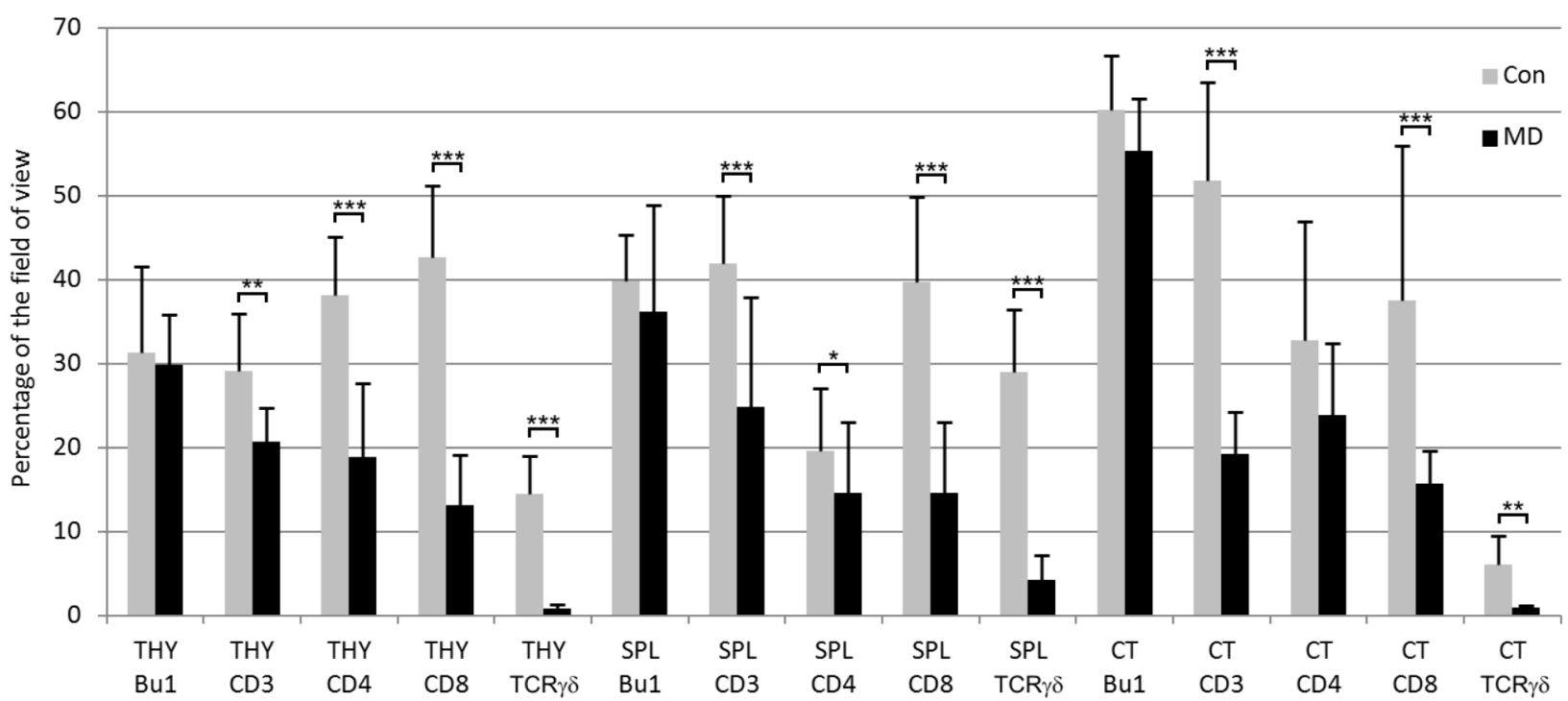

Fig. 4. Proportions of $\mathrm{Bu}^{+}, \mathrm{CD}^{+}, \mathrm{CD}^{+}, \mathrm{CD} 8 \alpha^{+}$and $\mathrm{TCR} \gamma \delta^{+}$cells (mean $\pm \mathrm{SD}$ ) in lymphoid organs. Con - control, $\mathrm{MD}$ - Marek's disease, THY - thymus, SPL - spleen, CT - cecal tonsil $\left({ }^{*} p<0.05 ;{ }^{* *} p<0.01 ; * * * p<0.001\right)$.

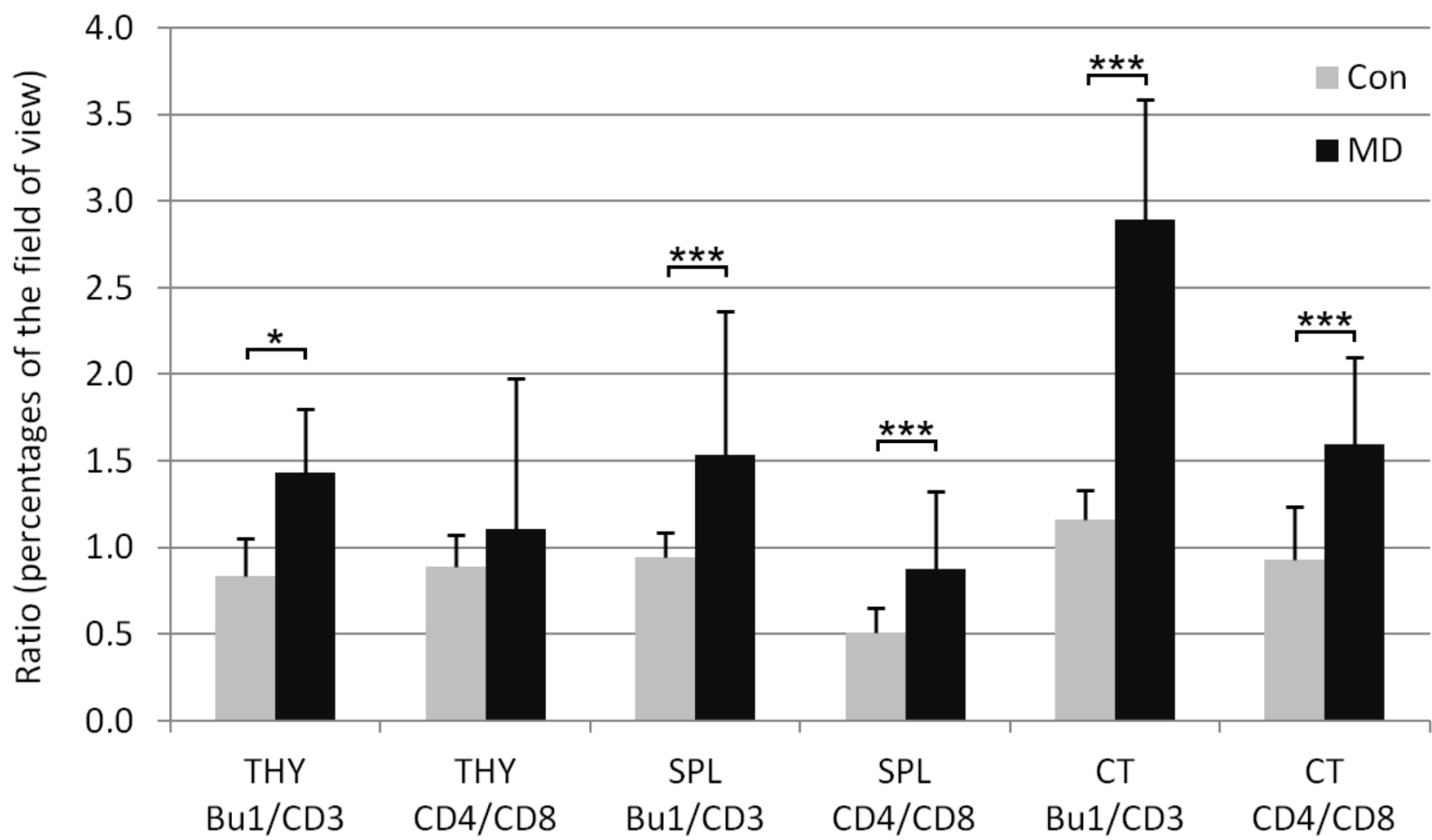

Fig. 5. $\mathrm{Bu}^{+} / \mathrm{CD}^{+}$and $\mathrm{CD}^{+} / \mathrm{CD}^{+}$cell ratios (mean $\pm \mathrm{SD}$ ) in lymphoid organs. Con - control, MD - Marek's disease, THY - thymus, SPL - spleen, CT - cecal tonsil $\left(* p<0.05 ;{ }^{* * *} p<0.001\right)$.

In non-lymphatic organs of $\mathrm{MD}$ group, the tumors mainly consisted of $\mathrm{CD}^{+}{ }^{+} \mathrm{CD} 4^{+}$cells, whereas $\mathrm{Bu}-1^{+}$ and $\mathrm{CD} 8^{+}$cells were sparse and probably infiltrated the tumor later as a part of inflammatory reaction. On the periphery of the tumors, mild infiltration of $\mathrm{Bu}-1^{+}$ and $\mathrm{CD}^{+}$cells was observed whereas in the center of lymphomas these cells were sparsely distributed.

\section{Morphometry}

The area that had been immunohistochemically stained by reaction with antigen-positive cells was measured and expressed as the percentage of the field of view. For the purposes of this paper, the proportion of cells in the field of view was defined as the cell number. 
In the thymus of hens from MD group, the number of $\mathrm{CD}^{+}, \mathrm{CD}^{+}, \mathrm{CD}^{+}$and $\mathrm{TCR} \gamma \delta+$ cells was significantly lower (CD3 $p<0.01$; CD4, CD8, TCR $\gamma \delta$ $p<0.001$ ) than that in the control hens (Fig. 4). The most evident decrease was observed in the number of $\mathrm{CD}^{+}$and $\mathrm{TCR} \gamma \delta^{+}$cells, which indicated populations of cytotoxic cells. In infected hens, the $\mathrm{Bu}-1^{+} / \mathrm{CD}^{+}$ ratio increased $(p<0.05)$ compared to that found in the control animals, but the $\mathrm{CD}^{+} / \mathrm{CD}^{+}$cell ratio remained unchanged (Fig. 5).

In the spleen from MD group, similar to the thymus, the number of $\mathrm{CD}^{+}, \mathrm{CD}^{+}, \mathrm{CD}^{+}$and $\mathrm{TCR} \gamma \delta^{+}$cells was significantly lower (CD4 $p<0.05$; $\mathrm{CD} 3, \mathrm{CD} 8, \mathrm{TCR} \gamma \delta p<0.001)$ than that in the respective control animals (Fig. 4). The spleen, similar to the thymus, was also shown to be highly depopulated from $\mathrm{CD}^{+}$and $\mathrm{TCR} \gamma \delta^{+}$cells. In the MD group, the $\mathrm{Bu}-1^{+} / \mathrm{CD}^{+}$and $\mathrm{CD} 4^{+} / \mathrm{CD}^{+}$cell ratios were significantly higher $(p<0.001)$ compared to those determined in the control animals (Fig. 5).

In $\mathrm{CT}$ derived from $\mathrm{v}+\mathrm{MDV}$ infected hens, the number of $\mathrm{CD}^{+}, \mathrm{CD}^{+}$and $\mathrm{TCR} \gamma \delta^{+}$cells was significantly lower (CD3, CD8 $p<0.001$, TCR $\gamma \delta p<0.01)$ compared to the respective control (Fig. 4). In this organ, similar to the spleen, the $\mathrm{Bu}-1^{+} / \mathrm{CD}^{+}$and $\mathrm{CD}^{+} / \mathrm{CD}^{+}$cell ratios were significantly higher in the MD group $(p<0.001)$ than those in the control hens (Fig. 5).

The cell composition in lymphomas selected from different non-lymphatic organs was also estimated. The $\mathrm{CD}^{+} / \mathrm{CD}^{+}$cell ratio was usually $6-15$ (in individual cases it was even above 30 ), whereas in organs from the control group only single lymphatic cells were present, at a ratio of approximately 1.1.

In the lungs a slight decrease in $\mathrm{B} / \mathrm{T}$ ratio and significant increase in $\mathrm{CD}^{+} / \mathrm{CD}^{+}$ratio (mean $\pm \mathrm{SD}$ $5.64 \pm 2.67$ v. $0.79 \pm 0.62$ in control) was also observed.

\section{Discussion}

There are two hypotheses that explain outbreaks of MD in adult chickens (Witter and Gimeno 2006). One theory is that such outbreaks are caused by recent challenge with highly virulent ( $\mathrm{vv}$ and $\mathrm{vv}+$ ) strains of MDV and is referred to as new infection hypothesis. An alternative theory, originally designated the old infection theory, is that late outbreaks are induced by exacerbation of an earlier MDV infection in adult flocks by as yet undiscovered environmental factors (Witter 2001). This study confirms previous observations that the break of vaccine immunity by highly virulent MDV strain induce the emergence of lymphomas which are generally similar, but significantly less evident, than those observed in the latent phase of MD in previously non-immunized chickens (Schat and Xing 2000, Witter and Gimeno 2006, Schat and Venugopal 2008). The presence of proliferative lesions also indicates the reaction of the immune system that can be observed as quantitative changes in lymphocyte number in central and peripheral lymphatic organs.

In this study the chickens originated from vaccinated commercial breeding flock with increased mortality were examined using PCR and direct sequencing of $m e q$ region for identification of very virulent + MDV. The characteristic pathological changes indicated the MD. However, the authors are aware that theoretically other, non-identified pathogens from the environment could contribute to this pathology.

The pathological changes in immune organs during the cytolytic phase of MD are characterized by bursal and thymic atrophy, lymphomatosis in the spleen, transient CT atrophy and loss of germinal centers in CT that persist during the latent phase of infection (Schat and Venugopal 2008, Heidari et al. 2014). Furthermore during latency, productive viral antigen cannot be detected in the bursa, thymus or spleen, and within 2 weeks the lymphocyte populations in the bursal follicles and thymic cortex return to normal range (Baaten et al. 2004). In the present study, thymus atrophy was more severely expressed in the MD group than in the control hens, where only physiological atrophy was present. However, lymphomatous lesions in the spleen and the loss of GC in CT were not observed.

In our study, an increase in the $\mathrm{Bu}-1^{+} / \mathrm{CD}^{+}$cell ratio in central and peripheral lymphatic organs in the infected hens was mainly a result of a significant reduction of $\mathrm{CD}^{+}$cell number accompanied by an unchanged number of $\mathrm{Bu}-1^{+}$cells. An increase in the $\mathrm{CD}^{+} / \mathrm{CD}^{+}$ratio was noted in peripheral lymphatic organs (SPL and CT) only, and resulted mainly from a significant decrease in $\mathrm{CD}^{+}$cell number with unchanged (CT) or marginally decreased (SPL) numbers of $\mathrm{CD}^{+}$cells. Intense emigration of $\mathrm{CD} 8^{+}$ and $\mathrm{TCR} \gamma \delta^{+}$cells from both central and peripheral lymphatic organs in the course of MD suggests a shift of CTLs from lymphoid organs to the places occupied by lymphomas. The occurrence of $\mathrm{CD} 8^{+}$cells in the periphery of tumors indicates that this subpopulation of immune cells is primarily engaged in reactions against MDV transformed cells. Previous studies suggest that these cells are also one of key factors involved in the protective mechanism induced by a vaccine strain (CVI988) (Kano et al. 2009). It was revealed that the $\mathrm{TCR} 1^{+} \mathrm{CD} 8^{+}$cell subpopulation was significantly and specifically increased in vaccinated-challenged chickens at 21 day post infection. 
Pejović et al. (2007) observed numerous CD79 positive cells (B cells) located mostly perivascularly in MD tumors in the liver. In the present study, the $\mathrm{B}$ cells were also observed in these regions of the liver forming small aggregates or scattered as single cells among numerous $\mathrm{CD}^{+}$cells. We have also found small numbers of diffused $\mathrm{Bu}-1^{+}$cells in tumor lesions from other non-lymphatic organs like kidneys, proventriculus, ovaries, skeletal muscles and nerves. This observation is consistent with that reported in studies of Pejović et al. (2007).

The lack of changes in B cell numbers in lymphatic organs and the slight infiltration of these cells around tumors in non-lymphatic organs suggests that humoral immunity does not participate substantially in defense response against $\mathrm{vv}+\mathrm{MDV}$ transformed cells. Unchanged or even decreased numbers of $\mathrm{CD} 4^{+}$ cells in lymphatic organs indicate that proliferation of transformed Th cells mainly occurs in non-lymphatic organs, whereas the quantitative changes of lymphocyte fractions in lymphatic organs results from the immune reaction of the bird.

\section{Conclusions}

This study has revealed that infection with field $\mathrm{vv}+\mathrm{MDV}$ strains can break post-vaccinal protection and influence the central and peripheral immune system. Decreases in $\mathrm{CD}^{+}$and $\mathrm{TCR} \gamma \delta^{+}$cell numbers in the thymus, spleen and cecal tonsils suggest that these cells are primarily engaged in cell-mediated cytotoxicity against MDV transformed cells during latency. The infiltration of CTL and B cells that appears around the tumors is unable to restrain the proliferation of MDV transformed cells, and often results in the death of the organism.

\section{Acknowledgements}

This research was financed by grant No. MWet/734/2013/SC from Wroclaw University of Environmental and Life Sciences (Poland). We would like to express our gratitude to Dr. Marcin Badowski and Dr. hab. Henryk Malec for their generous assistance in collecting material for our research. Publication is supported by Wrocław Center of Biotechnology, program: Leading National Research Center (KNOW) for the years 2014-2018.

\section{References}

Atkins KE, Read AF, Savill NJ, Renz KG, Islam AF, Walkden-Brown SW, Woolhouse ME (2013) Vaccination and reduced cohort duration can drive virulence evolution: Marek's disease virus and industrialized agriculture. Evolution 67: 851-860.

Baaten BJ, Butter C, Davison TF (2004) Study of host-pathogen interactions to identify sustainable vaccine strategies to Marek's disease. Vet Immunol Immunopathol 100: 165-177.

Baigent SJ, Smith LP, Nair VK, Currie RJ (2006) Vaccinal control of Marek's disease: current challenges, and future strategies to maximize protection. Vet Immunol Immunopathol 112: 78-86.

Burgess SC, Davison TF (1999) A quantitative duplex PCR technique for measuring amounts of cell-associated Marek's disease virus: differences in two populations of lymphoma cells. J Virol Methods 82: 27-37.

Davison F, Nair V (2005) Use of Marek's disease vaccines: could they be driving the virus to increasing virulence? Expert Rev Vaccines 4: 77-88.

Dudnikova E, Norkina S, Vlasov A, Slobodchuk A, Lee LF, Witter RL (2007) Evaluation of Marek's disease field isolates by the „best fit” pathotyping assay. Avian Pathol. 36: 135-143.

Haq K, Schat KA, Sharif S (2013) Immunity to Marek's disease: where are we now? Dev Comp Immunol 41: 439-446.

Heidari M, Fitzgerald SD, Zhang H (2014) Marek's disease virus-induced transient cecal tonsil atrophy. Avian Dis 58: $262-270$.

Hunt HD, Dunn JR (2013) The influence of host genetics on Marek's disease virus evolution. Avian Dis 57(2 Suppl): 474-482.

Hunt HD, Dunn JR (2015) The Influence of Major Histocompatibility Complex and Vaccination with Turkey Herpesvirus on Marek's Disease Virus Evolution. Avian Dis 59: 122-129.

Igyarto BZ, Nagy N, Magyar A, Olhh I (2008) Identification of the avian B-cell-specific Bu-1 alloantigen by a novel monoclonal antibody. Poult Sci 87: 351-355.

Kano R, Konnai S, Onuma M, Ohashi K (2009) Microarray analysis of host immune responses to Marek's disease virus infection in vaccinated chickens. J Vet Med Sci 71: 603-610.

Kodama H, Sugimoto C, Inage F, Mikami T (1979) Anti-viral immunity against Marek's disease virus infected chicken kidney cells. Avian Pathol 8: 33-44.

Mwangi WN, Smith LP, Baigent SJ, Beal RK, Nair V, Smith AL (2011) Clonal structure of rapid-onset MDV-driven $\mathrm{CD}^{+}$lymphomas and responding $\mathrm{CD} 8^{+} \mathrm{T}$ cells. PLoS Pathog 7: e1001337.

Omar AR, Schat KA (1996) Syngeneic Marek's disease virus (MDV)-specific cellmediated immune responses against immediate early, late, and unique MDV proteins. Virology 222: 87-99.

Omar AR, Schat KA (1997) Characterization of Marek's disease herpesvirus-specific cytotoxic $\mathrm{T}$ lymphocytes in chickens inoculated with a non-oncogenic vaccine strain of MDV. Immunology 90: 579-585.

Osterrieder N, Kamil JP, Schumacher D, Tischer BK, Trapp S (2006) Marek's disease virus: from miasma to model. Nat Rev Microbiol 4: 283-294.

Pejović N, Velhner M, Polaček V, Aleksić-Kovačević S, Marinković D, Knežević M (2007) Morphological and immunohistochemical examination of tumor cells in Marek's disease. Acta veterinaria (Beograd) 57: 27-35. 
Perumbakkam S, Hunt HD, Cheng HH (2014) Marek's disease virus influences the core gut microbiome of the chicken during the early and late phases of viral replication. FEMS Microbiol Ecol 90: 300-312.

Powell PC, Rennie M (1978) Marek's disease tumour-specific antigen induced by the herpesvirus of turkeys in vaccinated chickens. Vet Record 103: 232-233.

Ross LJN (1980) Mechanisms of protection conferred by HVT. In: Biggs PM (ed) Resistance and Immunity to Marek's disease. Commission of the European Communities, Berlin, pp 289-297.

Rothwell CJ, Vervelde L, Davison TF (1996) Identification of chicken $\mathrm{Bu}-1$ alloantigens using the monoclonal antibody AV20. Vet Immunol Immunopathol 55: 225-234.

Schat KA, Venugopal N (2008) Marek's disease. In: Saif YM (ed) Diseases of Poultry, Blackwell Publishing Ltd, Iowa State Press, pp 452-514.

Schat KA, Xing Z (2000) Specific and nonspecific immune responses to Marek's disease virus. Dev Comp Immunol 24: $201-221$

Venugopal K (2000) Marek's disease: an update on oncogenic mechanisms and control. Res Vet Sci 69: 17-23.

Witter RL (1996) Evolution of virulence of Marek's disease virus: Evidence for a novel pathotype. In: Silva RF, Cheng HH, Coussens PM, Lee LF, Velicer LF (ed) Current Research on Marek's Disease. American Association of Avian Pathologists, Inc., Kennett Square, PA, pp 86-91.
Witter RL (1983) Characteristics of Marek's disease viruses isolated from vaccinated commercial chicken flocks: association of viral pathotype with lymphoma frequency. Avian Dis 27: 113-132.

Witter RL (1997) Increased virulence of Marek's disease virus field isolates. Avian Dis 41: 149-163.

Witter RL (2001) Protective efficacy of Marek's disease vaccines. In: Hirai K (ed) Current topics in microbiology and immunology. Springer, Berlin, pp 58-90.

Witter RL, Calnek BW, Buscaglia C, Gimeno IM, Schat KA (2005) Classification of Marek's disease viruses according to pathotype: philosophy and methodology. Avian Pathol 34: 75-90.

Witter RL, Lee LF, Fadly AM (1995) Characteristics of CVI988/Rispens and R2/23, two prototype vaccine strains of serotype 1 Marek's disease virus. Avian Dis 39: 269-284.

Witter RL, Gimeno IM (2006) Susceptibility of adult chickens, with and without prior vaccination, to challenge with Marek's disease virus. Avian Dis 50: 354-365.

Woźniakowski G, Samorek-Salamonowicz E (2014) Molecular evolution of Marek's disease virus (MDV) field strains in a 40-year time period. Avian Dis 58: 550-557.

Zhang YP, Li ZJ, Bao KY, Lv HC, Gao YL, Gao HL, Qi XL, Cui HY, Wang YQ, Ren XG, Wang XM, Liu CJ (2015) Pathogenic characteristics of Marek's disease virus field strains prevalent in China and the effectiveness of existing vaccines against them. Vet Microbiol 177: $62-68$ 